\title{
Family Trimethylaminury Associated with Hereditary Angioedema
}

\section{Carlos Sánchez Salguero}

Allergy and Pneumology Unit. Pediatric Department. Saudi German Hospital. Dubai.

*Corresponding author: Carlos Sánchez Salguero, Allergy and Pneumology Unit. Pediatric Department. Saudi German Hospital. Dubai.

Received date: January 10, 2020; Accepted date: January 17, 2020; Published date: January 22,2020

Citation: Carlos S. Salguero., (2020) Family Trimethylaminury Associated with Hereditary Angioedema. J Clinical Research and Reports, 2(2); DOI:10.31579/jcrr.2020/018

Copyright: @ 2020 Carlos Sánchez Salguero, This is an open access article distributed under the Creative Commons Attribution License, which permits unrestricted use, distribution, and reproduction in any medium, provided the original work is properly cited.

Abstract
There are patients who complain of giving off a fishy smell through the skin and sweat, which can be a cause of
stress in which the doctor often fails to accept this situation, or even the patient or his family members are
ashamed of communicate these symptoms, causing their isolation.
Trimethylaminuria, also called fish smell syndrome or fish smell syndrome [1], is a very rare metabolic disorder
that presents an autosomal recessive inheritance pattern, causing an alteration in the function of the enzyme
flavinmonooxygenase 3 (FM03 ) [2,3].
On the other hand, the presence of alterations in the inflammatory chain that governs the complement cascade
is responsible for clinical situations that require an accurate diagnosis, such as Hereditary Angioedema, since
their evolution can be the origin of clinical complications, serious times
We present a case of family Trimethylaminuria in which the affected are two brothers of 2 and 6 years, and
whose diagnosis could be obtained since the male patient presented an outbreak of inflammation of the face
finally identified as Hereditary Angioedema.
Keywords: trimethylaminuria; paediatric; hereditary angioedema

\section{Introduction}

It was in 1970 when the first reference known to Trimethylaminuria was published in the medical journal Lancet [4], but references in the literature dating back several thousand years have been identified. Thus, one of the first descriptions of the disease is described in the play "The Tempest" by William Shakespeare, in which one of the characters named Caliban is described, as follows: "He smells like fishy; a tremendously ancient and smelly fish .... "

Trimethylaminuria can be primary, genetic, or secondary [5]. The primary form is due to an autosomal recessive disorder caused by the mutation of the FMO3 gene located on the long arm of chromosome 1 (1q24.3) [6] or by reduced enzymatic expression. This gene is very polymorphic; In fact, at least 40 mutations, alone or in combination, have been described that are associated with a greater or lesser activity of the enzyme, giving clinical manifestations of varying intensity.

The most severe cases have been related to mutations P153L and E305X [7]. Transient forms related to factors that modify the oxidative capacity of the enzyme have been described: viral infections, immaturity of the oxidative system (prematurity), enzyme inhibitors, excess of dietary precursors of TMA [8] and hormonal factors (menstruation). These intermediate forms usually appear in heterozygous individuals [9]. Secondary forms are due to kidney or liver lesions.

The first symptoms usually appear in childhood, but in most cases the diagnosis is delayed due to ignorance of this disease. Unlike other metabolites, high levels of TMA are not toxic, but this disease should not be considered benign, since body smell can cause serious psychosocial problems (social isolation, low self-esteem, depression, even suicide), as a consequence of rejection social to which those who suffer from it are subjected, most often affecting women.

Therefore, if FMO3 does not work correctly, or the enzyme is not produced by the body's enzyme systems, the ability to degrade trimethylamine (TMA), produced by precursors found in the diet, towards the production of the compound is lost. Inactive trimethylamine oxide (OTMA) through a process known as $\mathrm{N}$ oxygenation. The trimethylamine thus produced accumulates in the body and is released through perspiration, urine and breath giving them a strong fishy smell.

The diagnosis is based on a standard search test for TMAU in which the relationship between trimethylamine and trimethylamine oxide in urine is measured. There is a test available that allows a genetic 
analysis. The main enzyme responsible for the $\mathrm{N}$-oxygenation of trimethylamine is encoded by the FMO3 gene.
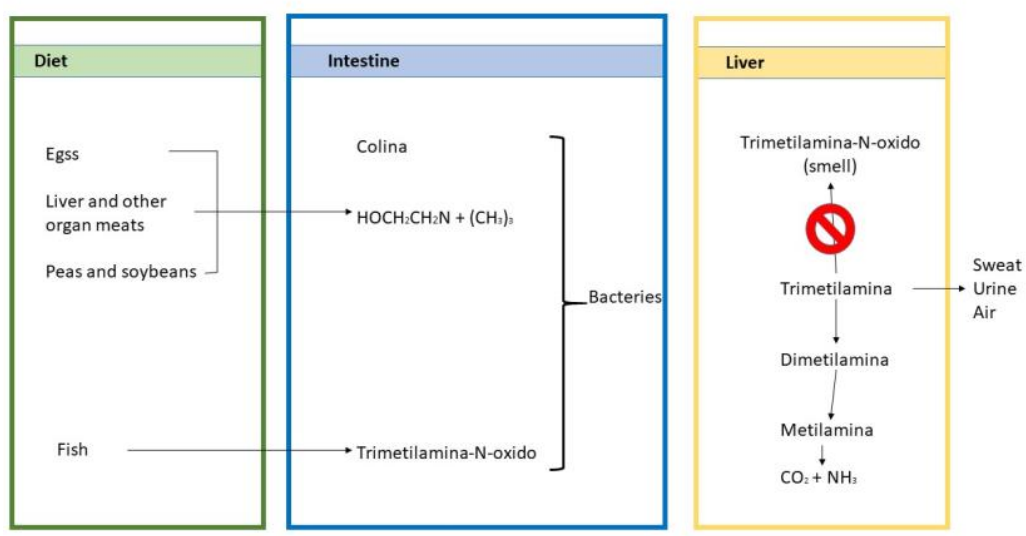

Figure: 1

To confirm this disease, although sometimes the clinical description of the patients is sufficient, it is necessary to perform a fish-rich diet test that consists of eating a diet that contains fish, and analysing samples of the urine removed in the next 48 hours. This allows us to analyse creatinine, trimethylamine (TMA) and TMA N-oxide (TMAO) in addition to the TMA / TMAO ratio.

A similar test can be used to identify healthy carriers of this condition (i.e. those individuals who have a copy of the mutated gene, but show no symptoms since with the remaining copy under normal conditions it is enough for them to manage TMA levels incorporated with the diet). In these carrier individuals, urine trimethylamine levels can be measured after a high dose of choline (one of the precursors of trimethylamine). An elevated level of TMA is indicative of the presence of the mutated gene.
Many times finding the cause of this disorder is a slow process, not always taken into account as the first diagnosis by paediatricians, since it is a not very well know illness, so it can be delayed up to 10 years.

We can have several diagnostic tests among which are:

\section{Fish-rich diet test}

Children affected by TMA (FMO3 deficit) are evaluated, who must show an initial increase in TMAO followed by a large increase in TMA while TMAO falls. An unaffected person should show a marked increase in TMAO but no increase in the concentration of TMA.

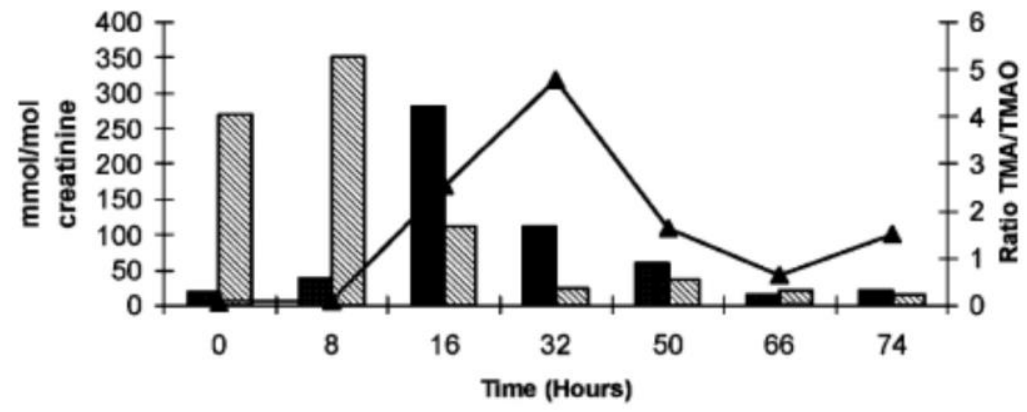

Figure 2 
Adult control 2

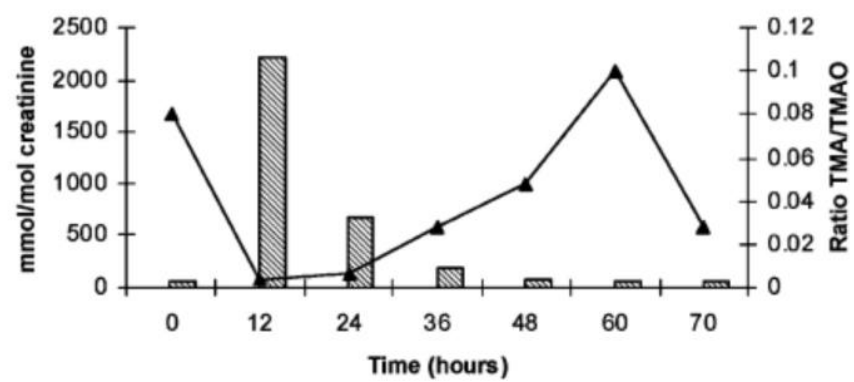

Figure 3

\section{Choline test}

Choline is administered orally in the form of choline bitartrate, dissolved in water or orange juice and analysing samples of the urine removed in the following 48-72 hours. Analyse creatinine, trimethylamine (TMA) and oxidized TMA (TMAO) and TMA / TMAO ratio. Assessment: children with TMA (FMO3 deficit) should show a rapid increase in TMA with a smaller increase in TMAO, and an increase in the ratio. An unaffected patient should show a marked increase in TMAO but no increase in the concentration of TMA and accompanied by a decrease in TMA / TMAO ratio.

Patient

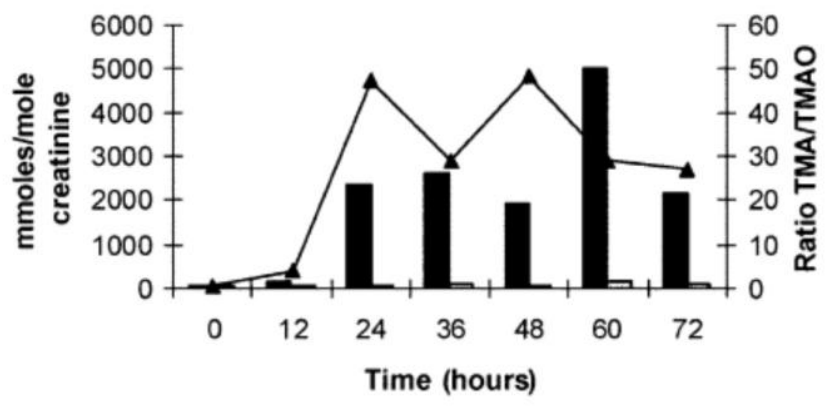

Figure 4

\section{Adult control}

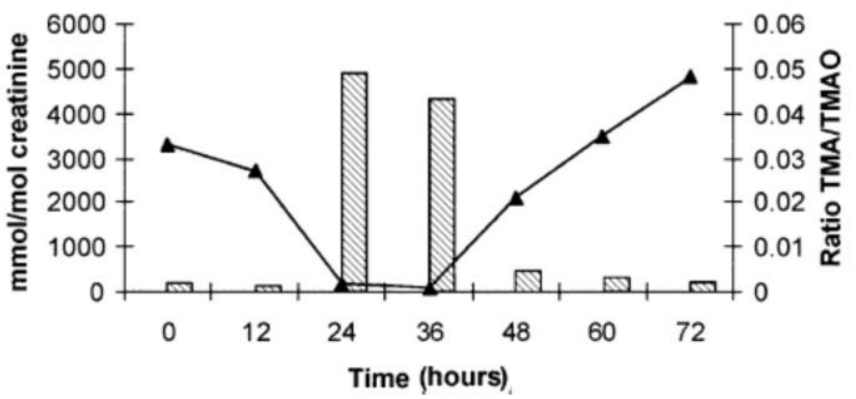

Figure 5 
Currently we do not have an enzymatic treatment that can replace the deficit that these patients present, so the only valid resource is the diet free of foods containing choline and TMAO.

\section{Clinical case}

The case we present in this article is about a family that affects two adjuvant enzymatic problems that originate two different processes, on the one hand trimethylaminuria to which hereditary angioedema type I is added.

The initial patient is a 6-year-old male who comes to the hospital's paediatric emergency department since presenting a picture of inflammation and oedema that affects half of the face from 6 hours before, without referring to the presence of pain or pruritus of the affected area, being the first time you develop this clinical picture.

On physical examination, there is an increase in the consistency of the subcutaneous cellular tissue of the right part of the face that affects the cheek without extension to the forehead or neck. It is found that the area is hotter to the touch, although the patient does not report the presence of pain or itching, only a feeling of swelling. It does not present breathing difficulties or swallowing or chewing food. There are no other areas of the body that show inflammation or oedema.

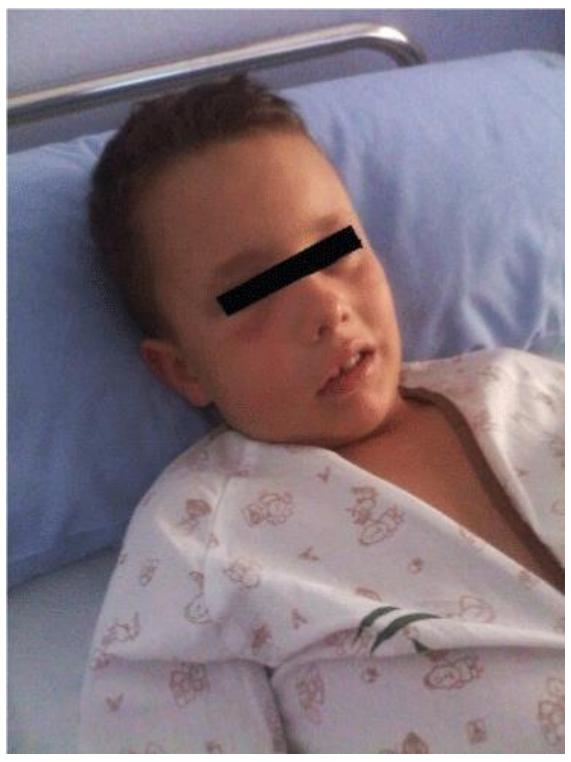

Figure 6

After being kept under hospital observation, blood samples are taken for complementary studies in which haematological and immunological values are checked: leukocytes $8500 / \mathrm{mm} 3$, neutrophils $48 \%$, lymphocytes $39 \%$, eosinophils $4.5 \%$. The allergen triggering factor was also studied by stool test, negative for parasites, as well as urine tests; immunoglobulin E was $101 \mathrm{mg} / \mathrm{dL}$. Antinuclear antibodies (ANA) and antimitocontrial antibodies (ANCA) were negative. Complement levels were normal for C3 (165 $\mu \mathrm{g} / \mu \mathrm{L})$ and decreased for $\mathrm{C} 4(1.2 \mu \mathrm{g} / \mu \mathrm{L})$ so the study was extended to $\mathrm{C} 1$ esterase with a decreased value of $5.2 \mu \mathrm{g} / \mu \mathrm{L}(24-39 \mu \mathrm{g} / \mu \mathrm{L})$, which confirmed the diagnosis of angioedema due to deficit of C1 inhibitor.

The evolution in the following hours was satisfactory with remission of oedema and inflammation of the face and without extension to other areas of the body, so he was discharged and cited in Paediatric Allergy consultations to continue conducting further laboratory studies.

It is also requested that the 3-year-old sister go to the patient to determine if she has blood values that allow us to make a previous diagnosis and thus ensure effective treatment in case of clinical symptoms.
The patient's sister has a normal physical examination and has not reported, according to the parents, the presence of compatible pictures of inflammation or oedema of the body. It is necessary to carry out the same studies as in the sibling and normal values are obtained for blood count, IgE, study of parasites in feces and negative for ANCA type antibodies, however it presents a decrease in the levels of $\mathrm{C} 4(1.5 \mu \mathrm{g} / \mu \mathrm{L})$ and $\mathrm{C} 1$ esterase $4.3 \mu \mathrm{g} / \mu \mathrm{L}$ with normal value of C3 (121 $\mu \mathrm{g} / \mu \mathrm{L})$, confirming also the diagnosis of C1 congenital deficit, important data in the future if there were signs of inflammation of some area of your body.

During the realization of the medical history, the parents report a fact that catches their attention, as when they eat fish, both brothers, the skin and sweat smell of fish, with an unpleasant smell, and that is why they have stopped contributing Fish in the diet of both children.

On suspicion of trimethylaminuria syndrome we proceed to perform an oral provocation test in the hospital, with $150 \mathrm{gr}$ of fried hake. After the meal, the patients do not report oral pruritus damage or skin or digestive involvement with pathological character, however, at 6 hours after the end of the oral test, an intense smell of rotten fish is found in the room, more intense the customized smell that the examiner was closer to both patients. 
Finally, the levels of creatinine, trimethylamine (TMA) and N-oxide of TMA (TMAO) were determined in addition to the TMA / TMAO ratio, showing a decrease in TMAO levels compared to the increase in TMA levels and by both of the TMA / TMAO ratio.

With the diagnosis of trimethylaminuria syndrome, genetic study determination is requested for confirmation of the syndrome, although it is not necessary since we have positive clinical and laboratory tests. In the genetic report of both patients there is an autosomal recessive inherited disorder caused by homozygous mutations in the monooxygenase-3 gene that contains Flavin (FMO3; 1q24.3).

\section{Discussion}

Trimethylaminuria, or also known as fish smell syndrome, is a metabolic disorder first described in 1974 [1], and is due to the abnormal excretion of trimethylamine through urine, sweat, breath and vaginal secretions.

It can be a primary or secondary disorder that affects the liver or kidney, or it can be caused by trimethylamine precursors such as choline, lecithin or carnitine present in the patients' diet. [1] The primary syndrome is inherited in an autosomal recessive way, due to a defective enzyme called Monooxigenasa 3 that has Flavin in its composition, whose gene responsible for production called FMO3, is defective in the 1q23-25.5 region.

Less than 300 patients with trimethylaminuria with more than 30 different mutations and more than 40 polymorphisms have been described in the literature $[11,12,13]$. It is a rare disorder, but the exact prevalence is unknown. However, it is much higher than expected [10].

There are common causes that cause the smell of rotten fish in a patient such as poor hygiene, presence of gingivitis, bacterial infections located in the vagina and urine or even urinary tract infections, and even advanced diseases that affect the liver or to the kidney And even congenital errors of amino acid metabolism associated with a peculiar smell are described in glutaric aciduria type II and isovaleric acidemia (sweaty feet), hawkinsinuria (pool), 3-hydroxy-3-methylglutaric aciduria (cat urine) , multiple carboxylic deficiency (cat urine), urine disease with maple syrup (maple syrup), hypermethioninemia and tirosinemia (boiled cabbage), phenylketonuria and trimethylaminuria (rotten fish). [10]

Associations of trimethylamuria and endocrinological diseases such as hypothyroidism have been described (15), however the association of two metabolic diseases such as trimethylaminuria and hereditary angioedema, after reviewing all the literature presented, is the first time we can review it.

It has been found that some metabolic disorders could be related to psychiatric disorders. Phenylketonuria, homocystinuria, cobalamin defects, Niemann Pick type C syndrome, mucopolysaccharidosis type III, creatine synthesis and transport defects, purine and pyrimidine metabolism disorders and trimethylaminuria are well known examples. Attention deficit syndrome with hyperactivity, autism spectrum disorders, schizophrenia, dementia, anxiety and mood disorders are some of the psychiatric symptoms related to metabolic diseases. Psychosocial problems related to trimethylaminuria, such as low self-esteem, social isolation, anxiety, depression, paranoia, poor school and academic performance and even suicide attempts are well described in the literature $[10,14]$.

Although it is a difficult diagnosis to identify initially, when reviewing the literature, it is clear that the problem lies in a foul-smelling body secretion, in fact Mayatepek et al studied two babies with transient trimethylaminuria in childhood. Both had skin and urine with a fishy smell. Similarly, both had normal initial routine physical and biochemical parameters before the urine was analysed for TMA [16].

The diagnosis of trimethylaminuria is a combination of clinical, biochemical and genetic tests. Urine can be tested for free TMA alone or in combination with its $\mathrm{N}$-oxide metabolite. Samples from affected individuals show abnormally high levels of free TMA or a high proportion of TMA and its $\mathrm{N}$ oxide. With the use of molecular genotype techniques and recognition of the causative mutation of the FMO3 gene and its many polymorphs, the genetic type Primary can be easily identified [1].

The basis of treatment for the disorder is dietary restrictions, targeting food groups that contain high levels of TMA, including its precursors, such as carnitine and choline, and TMA N-oxide. In particular, foods such as eggs, liver, beans and shellfish should be avoided. [1.17].

Other beneficial treatments are antibiotics such as metronidazole, neomycin and amoxicillin that can be used in short cycles to suppress intestinal bacteria, which reduces the production of TMA [18]. The use of intestinal absorbers such as carbon to retain the production of TMA can also play a role. In addition, the use of soaps, lotions and fragrances can temporarily mask the smell in this condition. It can also be beneficial to educate people about the condition through dietary advice, as well as addressing exacerbating factors such as stress and menstruation.

In the patients we described, the stress and nervousness caused by the bad smell of the skin was considered as a trigger for the primary angioedema reaction in the male. Thus, once one of the causes that in the future could favour the presence of new angioedema attacks was identified, the child's self-esteem was reinforced through psychology sessions, which until now have been effective since the patient, a year after the first crisis of angioedema, has not returned to present more similar episodes. On the other hand, the younger sister was also included with the parents in the psychological reinforcement program to avoid stress situations that could trigger angioedema crisis, much more dangerous than the trimethylaminuria itself.

\section{Conflict of interests}

The author declares that he has no competing interests and that no financial support was obtained for the publication of this manuscript.

\section{References}

1. Mitchell SC, Smith RL (2001) «Trimethylaminuria: the fish malodor syndrome». Drug Metab Dispos 29 (4 Pt 2): pp. 517-521.

2. Treacy EP et al (1998) «Mutations of the flavin-containing monooxygenase gene (FMO3) cause trimethylaminuria, a 
defect in detoxication». Human Molecular Genetics 7 (5): pp. 839-845.

3. Zschocke J, Kohlmueller D, Quak E, Meissner T, Hoffmann GF et al (1999) «Mild trimethylaminuria caused by common variants in FMO3 gene». Lancet 354(9181): pp. 834-835.

4. Humbert JA, Hammond KB, Hathaway WE (1970) «Trimethylaminuria: the fish-odour syndrome». Lancet 2(7676): pp. 770-771.

5. Mazón Ramos A, Gil-Setas A, Berrade Zubiri S, Bandrés Echeverri T, Wevers $\mathrm{R}$ et al (2003) Primary trimethylaminuria or fish odor syndrome. A novel mutation in the first documented case in Spain. Med Clin (Barc). 120: 219-21

6. Montoya Álvarez T, Díaz Guardiola P, Olivar Roldán J, Elviro R, Wevers R, et al (2009) Trimetilaminuria: el síndrome de olor a pescado. Endocrinol Nutr. 56: 337-340.

7. Hernandez D, Addou S, Lee D, Orengo C, Shephard EA (2003) Phillips IR. Trimethylaminuria and a human FM03 mutation database. Hum Mutat. 22: 209-213.

8. Mitchell SC, Smith RL (2001) Trimethylaminuria: the fish malodor syndrome. Drug Metab Dispos. 29: 517-521.

9. Al-Waiz M, Ayesh R, Mitchell SC, Idle JR, Smith RL (1989) Trimethylaminuria: the detection of carriers using a trimethylamine load test. J Inherit Metab Dis. 12: 80-85.

10. Rehman HU (1999) Fish odor syndrome. Postgrad Med J; 75: 451-2.
11. Dolphin CT, Janmohamed A, Smith RL, Shephard EA, Phillips IR (1997) Missense mutation in flavin-containing mono-oxygenase 3 gene, FMO3, underlies fish-odour syndrome. Nat Genet; 17: 491-494.

12. Shephard EA, Treacy EP, Phillips IR (2014) Clinical utility gene card for: Trimethylaminuria-update Eur J Hum Genet $2015 ; 23$.

13. Motika MS, Zhang J, Zheng X, Riedler K, Cashman JR (2009) Novel variants of the human flavin-containing monooxygenase 3 (FMO3) gene associated with trimethylaminuria. Mol Genet Metab; 97: 128- 135.

14. Messenger J, Clark S, Massick S, Bechtel M (2013) A review of trimethylaminuria (fish odor syndrome). J Clin Aesthet Dermatol; 6: 45-48.

15. Li M, Al-Sarraf A, Sinclair G, Frohlich J (2011) Fish odour syndrome. CMAJ 2011; 183: 929-932.

16. Mayatepek E, Kohlmuller D (1998) Transient trimethylaminuria in childhood. Acta Paediatr; 87:1205-7.

17. Phillips IR, Shephard EA (2007) Trimethylaminuria. Oct 8 [Updated 2011 Apr 19]. In: Pagon RA, Adam MP, Ardinger $\mathrm{HH}$, et al, eds. GeneReviews $\AA$. Seattle (WA): University of Washington, Seattle, 1993-2015.

18. Treacy E, Johnson D, Pitt JJ, et al (1995) Trimethylaminuria, fish odour syndrome: a new method of detection and response to treatment with metronidazole. J Inherit Metab Dis; 18:306-312.

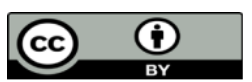

This work is licensed under Creative Commons Attribution 4.0 License

\section{To Submit Your Article Click Here: Submit Article}

DOI: $10.31579 /$ jcrr $/ 2020 / 018$
Ready to submit your research? Choose Auctores and benefit from:

$$
\begin{aligned}
& \text { * fast, convenient online submission } \\
& \text { rigorous peer review by experienced research in your field } \\
& \text { *apid publication on acceptance } \\
& \text { * authors retain copyrights } \\
& \text { - immedique DOI for all articles }
\end{aligned}
$$

At Auctores, research is always in progress.

Learn more https://www.auctoresonline.org/journals/journal-of-clinicalresearch-and-reports 